Brazilian Journal

of Chemical

ISSN 0104-6632

Printed in Brazil

Engineering

www.scielo.br/bjce

Vol. 35, No. 02, pp. 721 - 730, April - June, 2018

dx.doi.org/10.1590/0104-6632.20180352s20160670

\title{
FABRICATION OF SPINEL COATING ON HP40 ALLOY AND ITS INHIBITION EFFECT ON CATALYTIC COKING DURING THERMAL CRACKING OF LIGHT NAPHTHA
}

\author{
Binbin $\mathrm{Bao}^{1}$, Jinglei $\mathrm{Liu}^{1 *}$, Hong $\mathrm{Xu}^{1}$, Zhiyuan Wang ${ }^{2}$ and Kai \\ Zhang ${ }^{1}$
}

\begin{abstract}
${ }^{1}$ State-Key Laboratory of Chemical Engineering, School of Mechanical and Power Engineering, East China University of Science and Technology, Shanghai, 200237, China.

${ }^{2}$ School of Energy and Power Engineering, University of Shanghai for Science and Technology, Shanghai 200093, China.
\end{abstract}

(Submitted: December 1, 2016; Revised: April 26, 2017; Accepted: June 5, 2017)

\begin{abstract}
A novel two-step process of Cr-Mn pack cementation and thermal oxidation was applied to fabricate a $\mathrm{MnCr}_{2} \mathrm{O}_{4}$ spinel coating on HP 40 alloy. The Cr-Mn diffusion layer formed after the Cr-Mn pack cementation process is lacking in $\mathrm{Fe}$ and $\mathrm{Ni}$. A dense and uniform coating formed on the alloy following thermal oxidation. The coating is mainly composed of $\mathrm{MnCr}_{2} \mathrm{O}_{4}$ spinel phase, while the outer surface of the coating is completely $\mathrm{MnCr}_{2} \mathrm{O}_{4}$ spinel. The coating exhibits a favorable thickness of about $7 \mu \mathrm{m}$ according to SEM and EDS maps of its cross-section. The $\mathrm{MnCr}_{2} \mathrm{O}_{4}$ spinel coating significantly affects the coking mechanism and coke property according to coking experiments. Raman spectroscopy shows that the coated sample inhibits catalytic coke formation as more disordered carbon and amorphous carbon layers are present. Moreover, the coating is stable in coking and decoking environments.
\end{abstract}

Keywords: Pack cementation, Thermal oxidation, Spinel coating, Catalytic coking, Thermal cracking.

\section{INTRODUCTION}

Thermal cracking of hydrocarbons is the main process for producing ethylene, which is carried out in cracking coils. The cracking coils are usually made of $\mathrm{Fe}-\mathrm{Cr}-\mathrm{Ni}$ alloys, such as HP 40, HK 40, 35Cr45Ni. Coke accumulated on the inner surface of cracking coils will significantly increase the pressure drop and affect heat transfer from the coils to cracking gas, so that cracking furnaces have to be shut down periodically to burn off the coke, leading to the reduction of ethylene production. Therefore, coke formation on the inner surface of cracking coils is a constraint in steam cracking technology (Wang et al., 2008; Wang et al., 2007; Albright et al., 1988).

Catalytic coking is one of the main coking mechanisms during hydrocarbon thermal cracking, and which will not only accelerate coke formation but also lead to carburization. Catalytic coking is reported to be caused by the catalysis of $\mathrm{Fe}$ or $\mathrm{Ni}$ (Wang et al., 2007). In the case, a favorable way to prevent carburization and inhibit catalytic coking is 
to protect the coils with appropriate inert coatings. The compositions of coatings are usually ceramics and glasses (Li and Yang, 2004; Tang et al., 2014). In addition, Schietekat et al. (2015) developed a catalytic coating for anti-coking, which cannot only eliminate catalytic coking, but also convert radical coking to carbon oxides and hydrogen. Muñoz Gandarillas et al. (2014) comparatively investigated coking behaviors on both Al-enhanced alloys and non-Al containing alloys, and found that Al-enhanced alloys showed a better coking resistance. Moreover, coking resistance for non-Al containing alloys strongly depended on the relative concentration of $\mathrm{MnCr}_{2} \mathrm{O}_{4}$ in the surface, and $\mathrm{MnCr}_{2} \mathrm{O}_{4}$ was found to be largely unaffected by coking and decoking cycles. Shao et al. (2013) obtained $\mathrm{MnCr}_{2} \mathrm{O}_{4}$ composite scales with discrete blade-like structures on HK40 alloy by oxidation under low oxygen partial pressure, and the thickness of the scales is about $1 \mu \mathrm{m}$. $\mathrm{MnCr}_{2} \mathrm{O}_{4}$ composite scales show excellent anti-coking properties and strong bonding strength to the alloy matrix (Shao et al., 2013; Zhang and Albright, 2010). Li and Chen (2010; 2011) also proved that $\mathrm{MnCr}_{2} \mathrm{O}_{4}$ spinel is a stable material in a high temperature carbonaceous environment. Nonetheless, the $\mathrm{MnCr}_{2} \mathrm{O}_{4}$ composite scales formed by direct thermal oxidation exhibit some disadvantages, such as small thickness and heterogeneous structure, which can be partly attributed to the low content of $\mathrm{Mn}$ in the alloy matrix. The thin scales are easy to be damaged and subsequently lose their protective property due to the small thickness. Moreover, the discrete blade-like structures may provide extra places for coke to accumulate.

In this paper, a spinel coating was fabricated on a HP 40 alloy through a novel two-step process of Cr-Mn pack cementation and thermal oxidation. The spinel coating is mainly composed of $\mathrm{MnCr}_{2} \mathrm{O}_{4}$, which can resist coking well, and had a favorable thickness. The morphology and elemental distribution of both surface and cross-section, as well as phase composition of the coating were characterized. The stability of the coating in coking and decoking environments was also evaluated.
EXPERIMENTAL

\section{Fabrication of Spinel Coating}

The samples were cut from a HP40 alloy tube with a dimension of $10 \mathrm{~mm} \times 10 \mathrm{~mm} \times 3 \mathrm{~mm}$, and the main composition of the alloy is shown in Table 1. The samples were successively ground with 400, 600 and 800 grits $\mathrm{SiC}$ abrasive papers, and then ultrasonically cleaned in acetone. Then the samples were placed in a sealed retort in contact with powder and heated in a muffle furnace to perform the pack cementation process; the detailed $\mathrm{Cr}-\mathrm{Mn}$ pack cementation parameters are given in Table 2 .

After the Cr-Mn pack cementation process, the samples were placed in a quartz tube furnace to conduct the thermal oxidation process. The oxidation atmosphere was created by $\mathrm{H}_{2}-\mathrm{H}_{2} \mathrm{O}$ gas mixture in this work, and the gas mixture was generated by bubbling $\mathrm{H}_{2}$ through DI water at controlled temperature (293 $\mathrm{K})$. The generated $\mathrm{H}_{2}-\mathrm{H}_{2} \mathrm{O}$ gas mixture was introduced into the tube with a gas flow rate of $100 \mathrm{~mL} / \mathrm{min}$ after the tube was purified by $\mathrm{N}_{2}$ for 10 minutes. Afterward, the reaction tube was heated at a rate of $5 \mathrm{~K} / \mathrm{min}$ to $1323 \mathrm{~K}$. After isothermal holding for $20 \mathrm{~h}$, the reaction tube was cooled down to room temperature at a rate of $5 \mathrm{~K} / \mathrm{min}$.

\section{Coating Characterization}

The cross-sectional morphology and elemental distribution of the diffusion layer formed in the $\mathrm{Cr}$ $\mathrm{Mn}$ pack cementation process were characterized by scanning electron microscopy (SEM) and energy dispersive X-ray spectroscopy (EDX) line scan. The surface morphology and elemental composition of as-prepared coating were examined by SEM. X-ray diffraction (XRD) was adopted to detect the phase structure of the coating. The elemental composition and phase structure of the outer surface of the coating were characterized by EDX and Raman spectrum, respectively. The Raman spectrum was measured with a laser Raman

Table 1. The main composition of selected HP 40 alloy.

\begin{tabular}{lccccccccc}
\hline Element & $\mathrm{Ni}$ & $\mathrm{Cr}$ & $\mathrm{Mn}$ & $\mathrm{Si}$ & $\mathrm{C}$ & $\mathrm{Nb}$ & $\mathrm{P}$ & $\mathrm{S}$ & $\mathrm{Fe}$ \\
\hline $\begin{array}{l}\text { Content } \\
(\mathrm{wt} \%)\end{array}$ & 34.82 & 24.98 & 1.11 & 1.56 & 0.471 & 0.955 & 0.022 & 0.010 & 35.67 \\
\hline
\end{tabular}

Table 2. Chemical composition in wt $\%$ of the Cr-Mnpack cementation powder and pack cementation parameters.

\begin{tabular}{lccccc}
\hline Alloy & Cr-Mn agent & $\mathrm{Al}_{2} \mathrm{O}_{3}$ filler & $\mathrm{NH}_{4} \mathrm{Cl}$ activator & $\boldsymbol{T}(\mathrm{K})$ temperature & $\mathrm{t}(\mathrm{h})$ duration \\
\hline HP 40 & $35 \%$ & $63 \%$ & $2 \%$ & $1323 \mathrm{~K}$ & 6 \\
\hline
\end{tabular}


spectrometer, utilizing the $514.5 \mathrm{~nm}$ exciting line of an Ar-laser at room temperature, and recording in the range of $120 \sim 1000 \mathrm{~cm}^{-1}$. The cross-sectional morphology, thickness of the coatings were examined by SEM, and the elemental distribution of the cross-section was also confirmed by energy dispersive spectrometer (EDS) maps.

\section{Coking Experiments and Coke Characterization}

Coking experiments were carried out to evaluate the effect of the spinel coating on coke behavior during thermal cracking of light naphtha. The composition of light naphtha is shown in Table 3 , and the schematic diagram of the coking experimental apparatus is displayed in Figure 1. The coking experiments were performed according to the following conditions: the cracking temperature was $1123 \mathrm{~K}$, the cracking duration was from $1 \mathrm{~h}$ to $6 \mathrm{~h}$, the flow rate of feedstock was 180 $\mathrm{ml} / \mathrm{h}$, and the steam dilution ratio was $0.5 \mathrm{wt} \mathrm{H}_{2} \mathrm{O} /$ wt naphtha. The uncoated sample was oxidized in air at $1023 \mathrm{~K}$ for $14 \mathrm{~h}$ before the coking experiment to be in line with industrial practice. The mass of coke was determined by weighing the sample before and after coking, and the mean value of three repeated coking experiments was considered as the final mass of coke. After the coking experiments, the formed coke was characterized by SEM and Raman spectrum. The Raman spectrum was used to characterize the microstructure of the formed coke, and the measurement condition of coke was the same as that of the coating, except for recording in the range of $800 \sim 2000 \mathrm{~cm}^{-1}$. Moreover, to evaluate the effect of aging on spinel coatings under thermal cracking environment, the crosssection of the coating was examined by SEM and EDS analyses after 10 coking and decoking cycles. In each coking and decoking cycle, a $6 \mathrm{~h}$ coking experiment was followed by $30 \mathrm{~min}$ decoking; decoking was carried out at $1023 \mathrm{~K}$ by feeding air to the reactor.

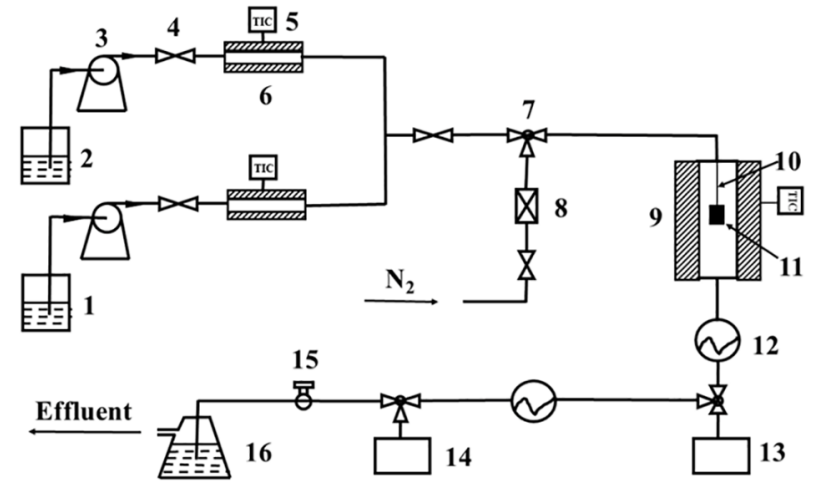

Figure 1. Schematic diagram of the coking experimental apparatus: (1) DI water; (2) naphtha; (3) metering pump; (4) needle valve; (5) temperature controller; (6) preheating furnace; (7) three-way valve; (8) gas flowmeter; (9) cracking furnace; (10) quartz fiber; (11) sample; (12) water cooling; (13) water condensate tank; (14) heavy hydrocarbon condensate tank; (15) ball valve; (16) purification plant.

\section{RESULTS AND DISCUSSION}

\section{Fabrication and Characterization of the Spinel Coating}

Figure 2 shows the cross-sectional morphology and elemental distribution of the alloy after the Cr-Mn pack cementation process. The diffusion coating has a uniform thickness of about $7 \mu \mathrm{m}$. It was found that the coating is rich in $\mathrm{Cr}$, lacks $\mathrm{Fe}, \mathrm{Ni}$ and $\mathrm{Si}$, with elevated concentration of Mn compared with that in the alloy matrix (about $1.0 \mathrm{At} \%$ ). When the thickness from the surface exceeded $7 \mu \mathrm{m}$, the concentrations of $\mathrm{Cr}, \mathrm{Fe}$, $\mathrm{Ni}$ and Si became close to those in the alloy matrix; however, the concentration of Mn decreased slowly with thickness.

High concentration of $\mathrm{Cr}$ and elevated concentration of $\mathrm{Mn}$ results in easier and faster formation of $\mathrm{MnCr}_{2} \mathrm{O}_{4}$ spinel in the subsequent oxidation process. Previous studies have reported that the rate of Mn diffusing and forming manganese oxide is about two orders of magnitude faster than that of $\mathrm{Cr}$ (Shao et al., 2013; $\mathrm{Li}$ and Chen, 2010). Consequently, $\mathrm{MnO}$ oxide would form on the surface instead of $\mathrm{MnCr}_{2} \mathrm{O}_{4}$ spinel when

Table 3. Composition of light naphtha.

\begin{tabular}{|c|c|c|c|c|c|}
\hline \multirow[b]{2}{*}{ Carbon number } & \multicolumn{5}{|c|}{ Mass concentration $(\%)$} \\
\hline & $\mathrm{N}$-alkane & Isoparaffin & Olefin & Naphthenes & Aromatics \\
\hline 5 & 2.84 & 1.74 & 0.16 & 0.67 & - \\
\hline 6 & 9.08 & 22.98 & 0.79 & 5.22 & 0.02 \\
\hline 7 & 3.77 & 17.23 & 0.35 & 10.51 & 0.35 \\
\hline 8 & 1.06 & 9.96 & - & 11.08 & - \\
\hline 9 & 0.32 & 1.56 & - & 0.29 & - \\
\hline Total & 17.07 & 53.47 & 1.3 & 27.78 & 0.37 \\
\hline
\end{tabular}


the concentration of $\mathrm{Mn}$ in the coating is high. Taking this into consideration, the concentration of $\mathrm{Mn}$ in the diffusion coating is controlled at a properly low level in the present work.

Figure 3 displays the SEM photographs of asprepared coating. The surface is fully covered by very small granular crystals with a small amount of bladelike structures scattered over the surface. As reported previously (Shao et al., 2013; Monteiro et al., 2011; Horita et al., 2002), Fe-Cr-Ni alloy (i.e., HP 40, HK $40,35 \mathrm{Cr} 45 \mathrm{Ni}$ ) exhibits blade type oxides and small thickness when directly oxidized at high temperature under low oxygen partial pressure. However, the CrMn coated alloy after thermal oxidation under the same condition shows a different morphology. The coating formed from the Cr-Mn coated alloy is obviously more dense and uniform. The XRD pattern (Figure 4) reveals that the coating is composed of $\mathrm{MnCr}_{2} \mathrm{O}_{4}$ spinel phase and $\mathrm{Cr}_{2} \mathrm{O}_{3}$ phase, and the peaks of $\mathrm{MnCr}_{2} \mathrm{O}_{4}$ spinel are much stronger than those of $\mathrm{Cr}_{2} \mathrm{O}_{3}$, indicating that the $\mathrm{MnCr}_{2} \mathrm{O}_{4}$ spinel phase is the major phase of the coating. Neither iron oxides nor nickel oxides are detected in this coating, which also indicates that selective oxidation of $\mathrm{Cr}$ and $\mathrm{Mn}$ was realized. EDX analysis (Figure 5(a)) shows that the coating surface consisted of $\mathrm{Mn}, \mathrm{Cr}$ and $\mathrm{O}$, and the atomic ratio of the three elements can well approximate that in the chemical formula of $\mathrm{MnCr}_{2} \mathrm{O}_{4}$. The Raman spectrum (Figure 5(b)) exhibits two obvious peaks at about 511 $\mathrm{cm}^{-1}$ and $685 \mathrm{~cm}^{-1}$. The strongest peak at around 685 $\mathrm{cm}^{-1}$ can be assigned to the $\mathrm{A}_{1 \mathrm{~g}}$ mode generated by the bonds in octahedral $\mathrm{Cr}^{3+} \mathrm{O}_{6}$, while the peaks at $511 \mathrm{~cm}^{-}$ ${ }^{1}$ and $600 \mathrm{~cm}^{-1}$ correspond to $\mathrm{F}_{2 \mathrm{~g}}$ and $\mathrm{E}_{\mathrm{g}}$ symmetries (Chen et al., 2007). As reported previously (Chen et al., 2007; Gupta et al., 1993; Bao et al., 2016; Proy et al., 2014), these peaks can be attributed to $\mathrm{MnCr}_{2} \mathrm{O}_{4}$ spinel. All the analyses indicate that the coating is mostly composed of $\mathrm{MnCr}_{2} \mathrm{O}_{4}$ spinel and the outer surface completely consists of $\mathrm{MnCr}_{2} \mathrm{O}_{4}$ spinel.

Before characterizing the cross-section of the spinel coating, the sample after thermal oxidation was coated with a Ni-layer by chemical plating to protect the coatings. Figure 6 shows the SEM photograph and EDS maps of the cross-section of the spinel coating. Ni plating, coating and alloy matrix can be distinctly found in the SEM photograph. The part in the middle
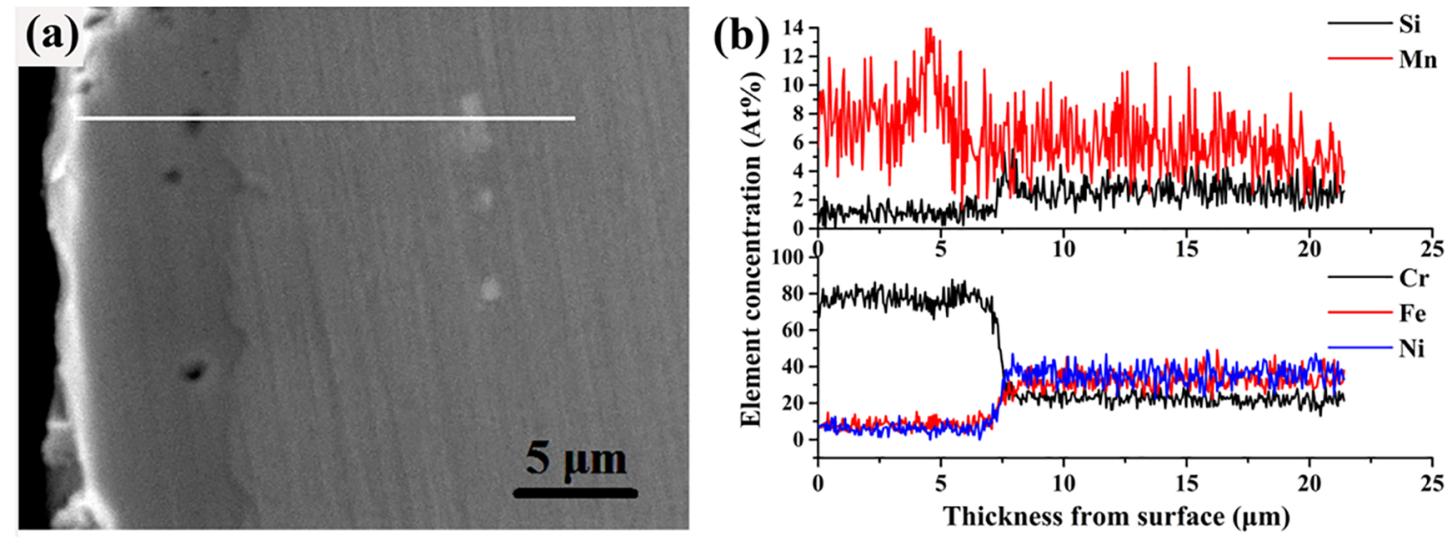

Figure 2. Cross-sectional morphology and elemental distribution of Mn-Cr coated alloy sample: (a) cross-sectional morphology; (b) elemental distribution of the cross-section.
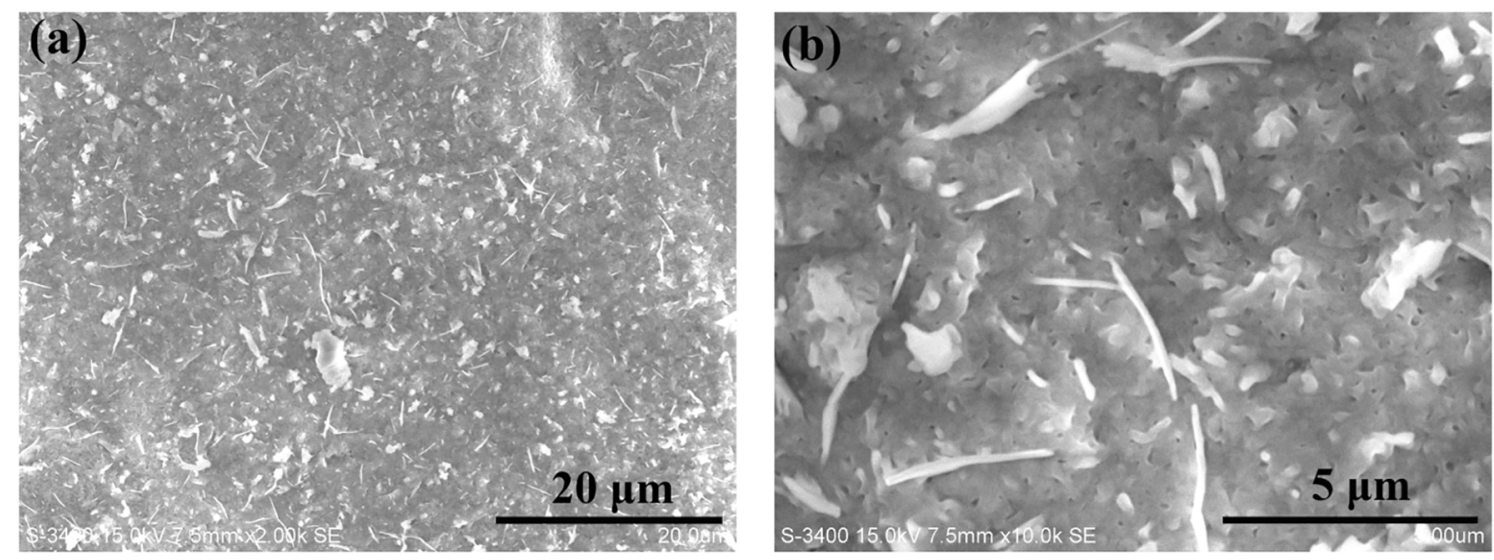

Figure 3. Surface morphology of the as-prepared coating. 


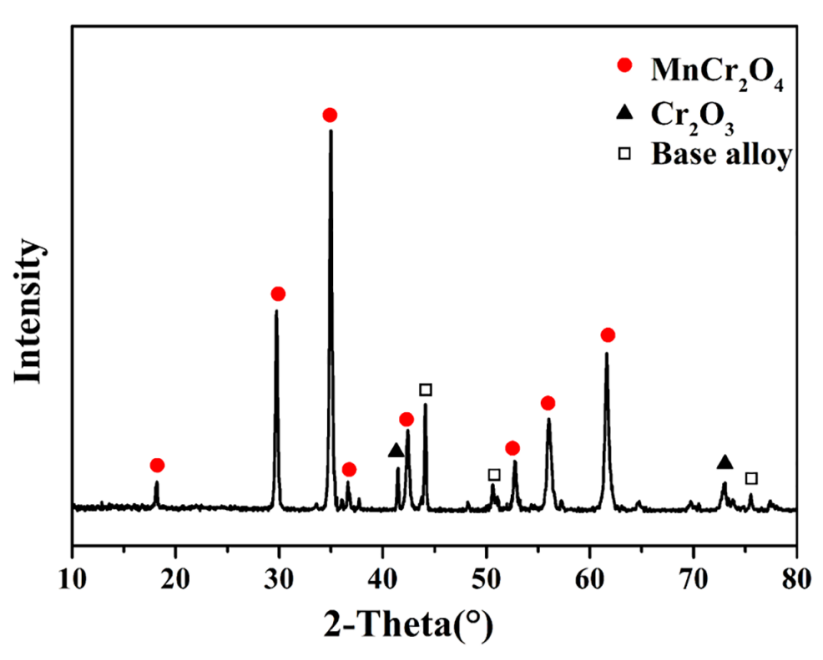

Figure 4. XRD pattern of the coated sample.

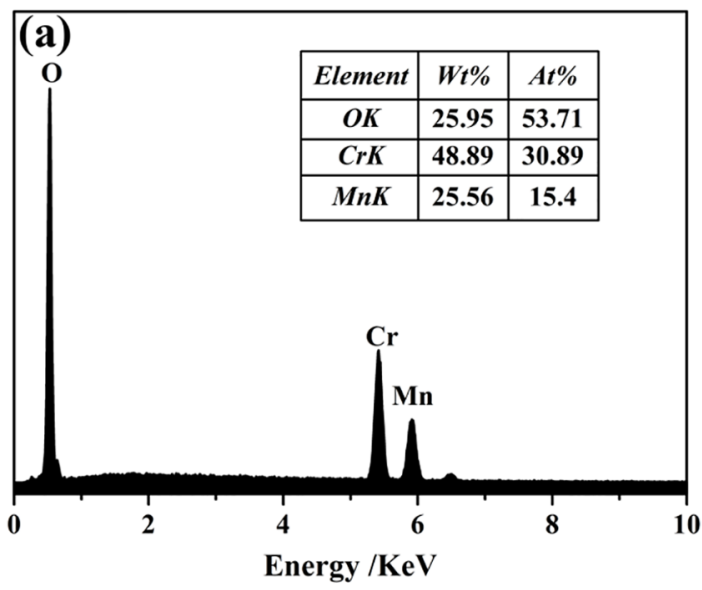

corresponds to the spinel coating, which is uniform and dense, with a thickness of about $7 \mu \mathrm{m}$. EDS maps indicate that the coating consists of $\mathrm{Cr}, \mathrm{Mn}$ and $\mathrm{O}$, which coincided with the analyses above. Moreover, a discrete layer of Si-rich oxide is found between the coating and alloy matrix, which is probably $\mathrm{SiO}_{2}$.

Among all the oxide-forming elements in the alloy, $\mathrm{Mn}, \mathrm{Cr}$ and Si can be oxidized under the experimental atmosphere (Shao et al., 2013; Li and Chen, 2010; $\mathrm{Li}$ and Chen, 2011; Li et al., 2009). Cr is oxidized first in the initial oxidation stage because of its higher thermodynamic activity (Li and Chen, 2010). Afterward, because Mn diffuses in the alloy much faster than $\mathrm{Cr}$, Mn can quickly diffuse outward and form $\mathrm{MnO}$ oxide, and then react with $\mathrm{Cr}_{2} \mathrm{O}_{3}$ to form $\mathrm{MnCr}_{2} \mathrm{O}_{4}$ (Li and Chen, 2010; Li and Chen, 2011).

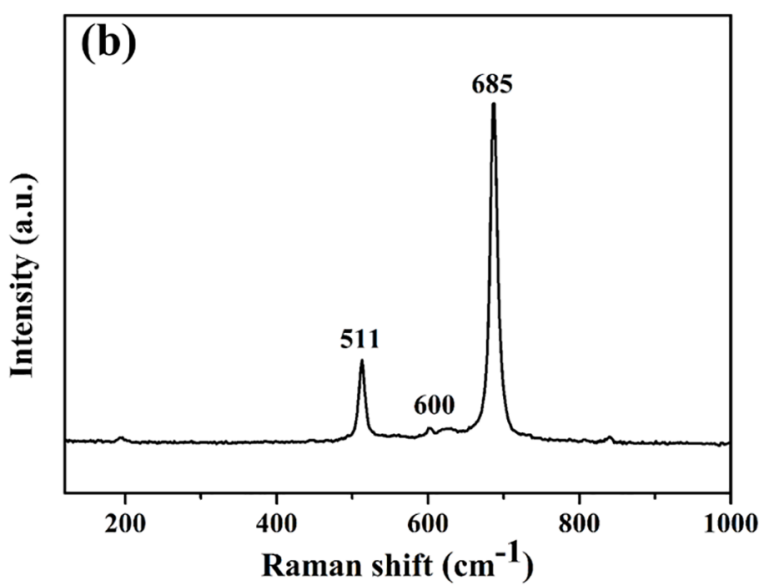

Figure 5. EDX analysis and Raman spectrum of the surface of the coating: (a) EDX analysis; (b) Raman spectrum.
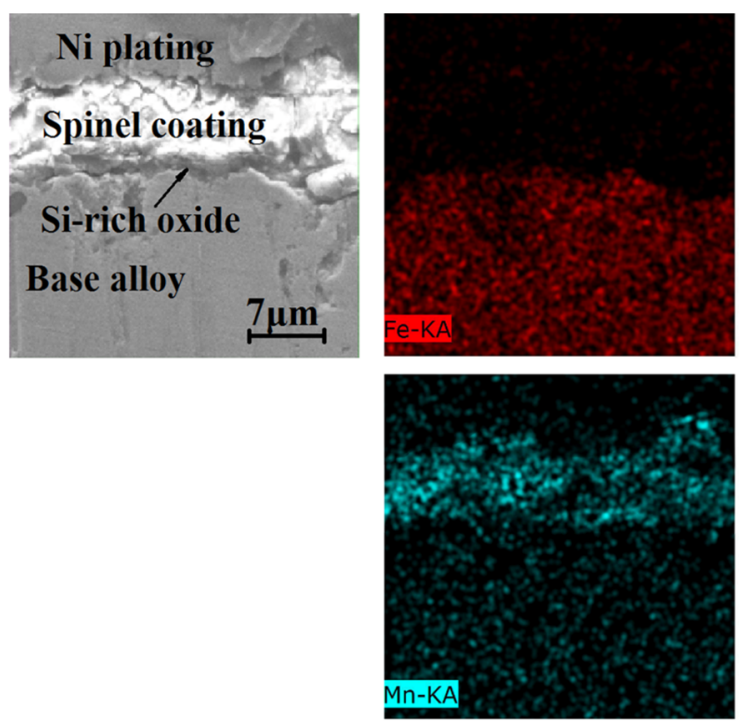
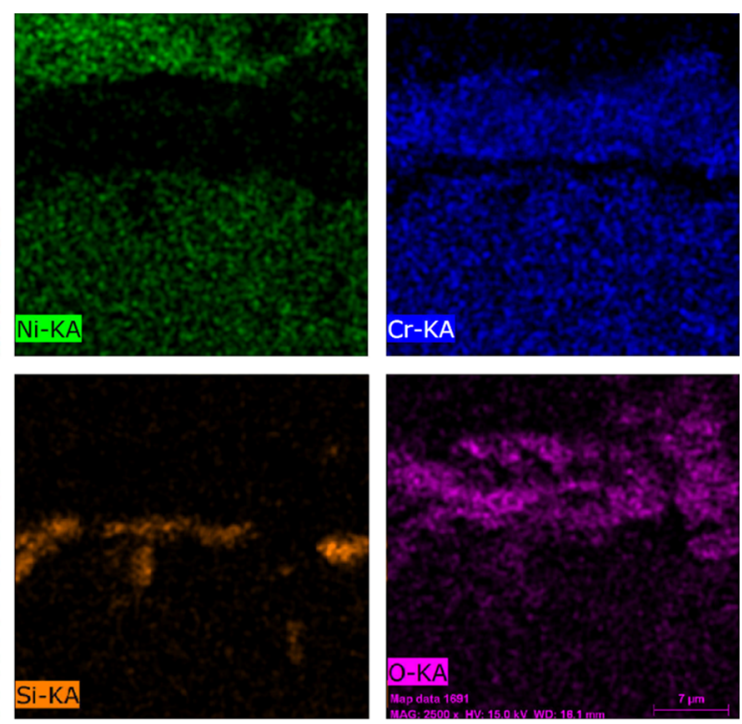

Figure 6. SEM photograph and EDS maps of the cross-section of spinel coating. 
The relative high concentrations of $\mathrm{Cr}$ and $\mathrm{Mn}$ in the diffusion layer result in the faster outward diffusion of the spinel-forming elements and the easier reaction to form a spinel coating. Therefore, the coating present in this work has dense structure and favorable thickness. However, the solubility of $\mathrm{Si}$ in $\mathrm{Cr}_{2} \mathrm{O}_{3}$ is low, so that $\mathrm{Si}$ can hardly diffuse out, resulting in a Si-rich oxide layer formed beneath the formed coating (Li et al., 2009). Similar Si-rich oxide was also reported by Huntz et al. (2007) and Shao et al. (2013).

\section{Effect of the spinel coating on coke properties}

Coking experiments were carried out on the spinel coated sample and uncoated sample. Figure 7 shows the morphology of cokes formed on both the coated sample and uncoated sample after $1 \mathrm{~h}$ thermal cracking. The uncoated sample surface is fully covered by coke filaments (Figure 7(a)), while only granular coke appears on the $\mathrm{MnCr}_{2} \mathrm{O}_{4}$ spinel coated sample (Figure 7(b)). The composition of the sample surface, which contacted with cracking gas, significantly affects the coking mechanism. Many researchers (Albright and Marek, 1988; Wang et al., 2011) have suggested that filamentous coke growth on uncoated alloy samples is catalyzed by $\mathrm{Fe}$ or Ni particles extracted from the base alloy (known as catalytic coking). And the process of filamentous coke formation can be summarized as follows: coking precursors adsorb on the surface of the alloy under thermal cracking environment, and further convert to carbon by a dehydrogenation reaction; the formed carbon reacts with $\mathrm{Fe}$ or Ni particles to form carbides, and then the carbides decompose into carbon and metal atomic clusters, which forms a catalytic reaction cycle; lastly, coke filaments continuously grow with the accumulation of carbon according to the catalytic reaction cycle above; at the same time, Fe or
$\mathrm{Ni}$ atomic clusters are lifted to the top of the filaments. A $\mathrm{MnCr}_{2} \mathrm{O}_{4}$ spinel coating is inert to cracking gas and stable in the thermal cracking environment. Therefore, the dense $\mathrm{MnCr}_{2} \mathrm{O}_{4}$ spinel coating could protect $\mathrm{Fe}$ or $\mathrm{Ni}$ particles from cracking gas, resulting in the elimination of catalytic coking. In the process of coke formation on a $\mathrm{MnCr}_{2} \mathrm{O}_{4}$ spinel coating, the coking precursors adsorb and convert to carbon on the surface of the coating, but the inert coating prevents the carbon from growing to form coke filaments. Then more coke accumulates on the coating through continuous adsorption and dehydrogenation of coking precursors on the coating as well as the formed coke, resulting in the granular appearance of coke. The appearance of only granular coke indicates that catalytic coking is eliminated on the coated sample.

Raman spectroscopy is sensitive to crystal structure as well as molecular structure, so that it is widely used to characterize the microstructure of materials, especially carbonaceous materials (Sadrjahani et al., 2010; Sadezky et al., 2005; Sheng, 2007). Coke is a well-known highly disordered carbonaceous material, and five bands at about $1200,1350,1500,1585$ and $1620 \mathrm{~cm}^{-1}$ are usually displayed in Raman spectra of coke (Sheng, 2007). Three coking experiments were carried out under the same condition, and cokes formed in the three experiments were all measured by Raman spectra. Figure 8 exhibits representative Raman spectra and curve fits for cokes formed on both the coated sample and uncoated sample during $1 \mathrm{~h}$ light naphtha thermal cracking. Two strong and overlapping peaks at about $1350 \mathrm{~cm}^{-1}$ and $1585 \mathrm{~cm}^{-1}$ are displayed in each Raman spectrum. The band around $1585 \mathrm{~cm}^{-1}$ (called the $\mathrm{G}$ band) corresponds to the stretching vibration mode with $\mathrm{E}_{2 \mathrm{~g}}$ symmetry in aromatic layers of ideal crystalline graphite, while the band around 1350 $\mathrm{cm}^{-1}$ (called the D1 band) corresponds to the graphitic lattice vibration mode with $A_{1 \mathrm{~g}}$ symmetry, which can be
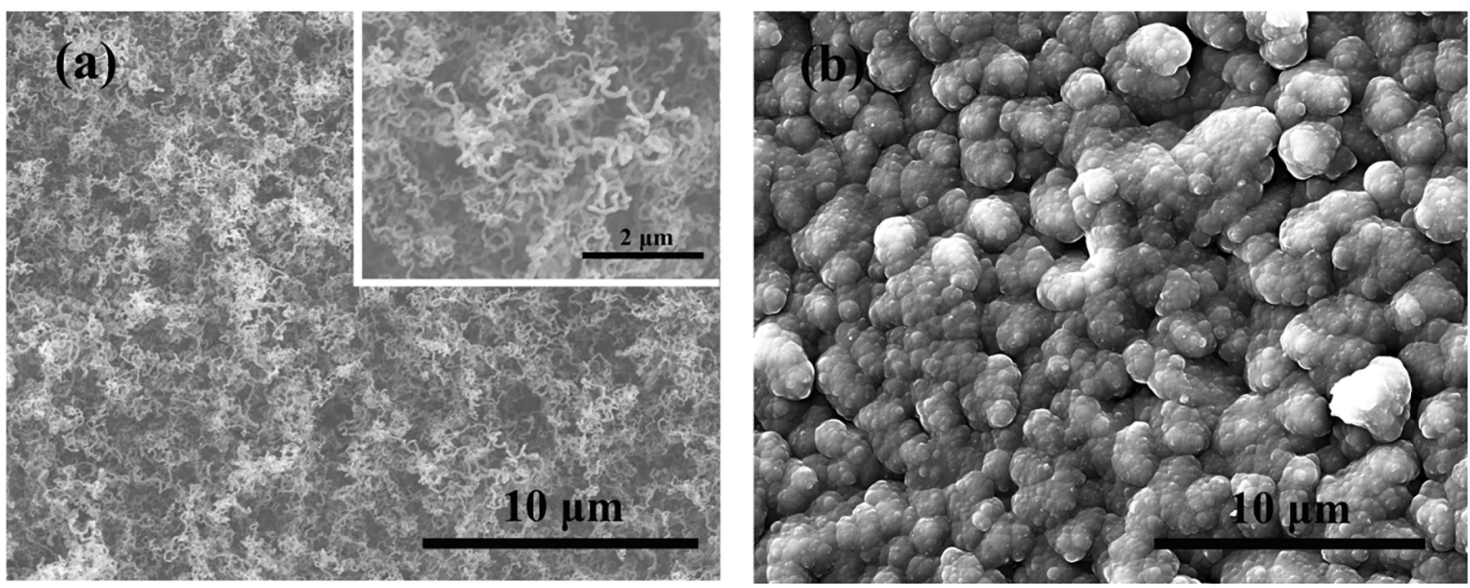

Figure 7. Morphology of cokes formed on coated sample and uncoated sample after $1 \mathrm{~h}$ light naphtha thermal cracking: (a) uncoated sample; (b) coated sample. 

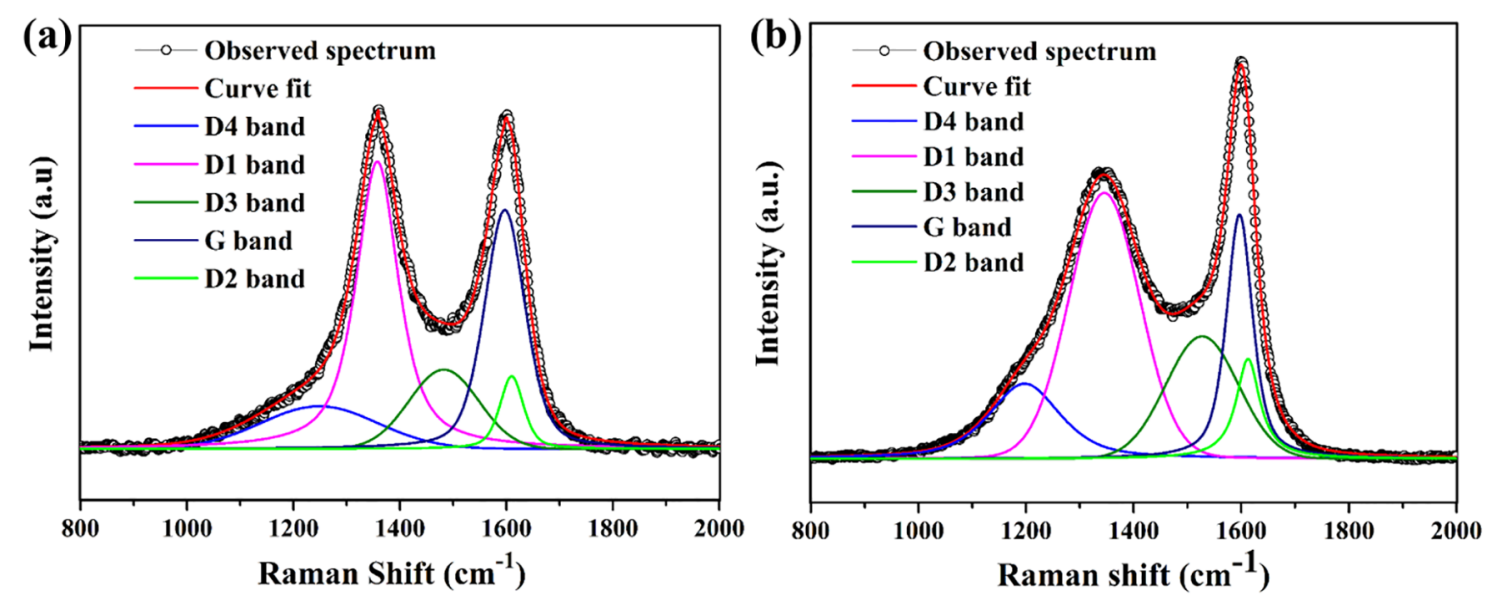

Figure 8. Representative Raman spectra and curve fits for cokes formed on both coated sample and uncoated sample during $1 \mathrm{~h}$ light naphtha thermal cracking: (a) uncoated sample; (b) coated sample.

attributed to in-plane defects and heteroatoms (Sadezky et al., 2005; Sheng, 2007). Each observed Raman spectrum shows a shoulder around $1200 \mathrm{~cm}^{-1}$, implying the present of another band (called the D4 band), reported to appear in very poorly organized carbonaceous materials (Sadezky et al., 2005). The high signal intensity between the D1 band and $\mathrm{G}$ band also indicates the appearance of another band around $1500 \mathrm{~cm}^{-1}$ (called the D3 band), which is suggested to originate from amorphous $\mathrm{sp}^{2}$-bonded forms of carbon (e.g., fragments, functional groups, organic molecules in poorly organized carbonaceous materials) (Sadezky et al., 2005; Sheng, 2007; Kawakami et al., 2005). Moreover, an additional band around $1620 \mathrm{~cm}^{-1}$ (called the D2 band) is suggested to appear when the D1 band is present, which is assigned to a lattice vibration analogous to that of the $G$ band but involving indirectly sandwiched graphene layers between other graphene layers (Sheng, 2007), hence the peak at about $1585 \mathrm{~cm}^{-1}$ comprises both the $\mathrm{G}$ band and D2 band. Therefore, five bands have to be taken into consideration when completely analyzing Raman spectra of cokes by curve fitting. Among them, four bands (G, D1, D2, D4) have Lorentzian shapes, while the D3 band has Gaussian shape (Sadezky et al., 2005; Sheng, 2007). The results of spectral decomposition in Figure 8 exhibit good agreement.

Figure 8 shows that the Raman spectra of coke formed on both coated and uncoated sample are qualitatively similar, but the relative peak intensities (band area) of each band are quantitatively different. According to many researchers (Sadezky et al., 2005; Sheng, 2007; Kawakami et al., 2005), the relative intensity of the $G$ band increases with the degree of graphitization, the intensity ratio of the D1 band and $\mathrm{G}$ band $\left(\mathrm{I}_{\mathrm{DI}} / \mathrm{I}_{\mathrm{G}}\right)$ has been proved to have good correlation with the degree of carbon structural order, and the intensity ratio of the D3 band and $\mathrm{G}$ band $\left(\mathrm{I}_{\mathrm{D} 3} / \mathrm{I}_{\mathrm{G}}\right)$ increases with the proportion of amorphous carbon.
Figure 9 exhibits the ratios of peak intensities derived from the decompositions of Raman spectra of cokes formed on uncoated and coated samples during $1 \mathrm{~h}$ light naphtha thermal cracking. The average relative intensities of the $G$ band (represented by the $\mathrm{I}_{\mathrm{G}} / \mathrm{I}_{\mathrm{All}}$ ratio) of coke formed on uncoated sample and coated sample are 0.28 and 0.16 , respectively, implying poor order of both cokes, as well as lower graphitization of coke formed on the uncoated sample. The average $\mathrm{I}_{\mathrm{DI}} / \mathrm{I}_{\mathrm{G}}$ ratios of coke formed on the uncoated sample and coated sample are 1.24 and 2.27, respectively, indicating a larger proportion of disordered graphite of coke formed on the coated sample. The average $\mathrm{I}_{\mathrm{D} 3} / \mathrm{I}_{\mathrm{G}}$ ratios of coke formed on the uncoated sample and coated sample are 0.31 and 0.95 , respectively, revealing more amorphous carbon of coke formed on the coated sample. In a word, the proportion of disordered graphite and amorphous carbon of coke formed on the coated sample is significantly larger than that of coke formed on the uncoated sample. The Raman spectral analyses coincide with the fact that filamentous coke has a higher degree of graphitization than granular coke in nature.

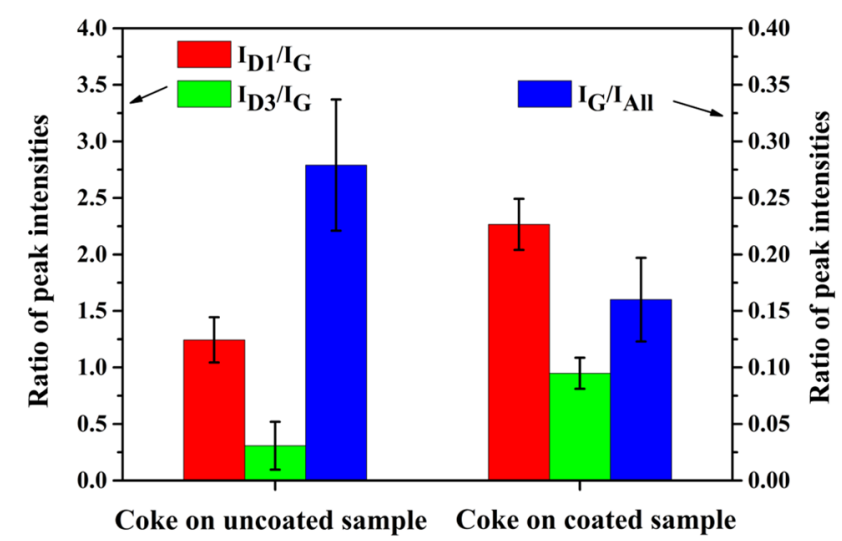

Figure 9. Ratios of peak intensities derived from the decompositions of Raman spectra of cokes formed on uncoated and coated samples during 1 $\mathrm{h}$ light naphtha thermal cracking. 


\section{Effect of the spinel coating on coking rate}

Coking experiments were conducted on both coated and uncoated samples. The amounts of coke deposited on the samples during different coking times are shown in Figure 10. The mass of coke formed on uncoated samples after $1 \mathrm{~h}$ coking time is $1.88 \mathrm{mg}$, while that on the coated sample is only $0.59 \mathrm{mg}$. The amounts of coke formed on both coated and uncoated samples increase with coking time, but the amounts of coke formed on coated samples increase more slowly. The amounts of coke formed on uncoated and coated samples after $6 \mathrm{~h}$ coking are $7.57 \mathrm{mg}$ and $2.76 \mathrm{mg}$, respectively. Therefore, the amounts of coke formed on coated samples are much lower than those formed on uncoated samples throughout the coking duration, indicating a significant inhibitory effect of the spinel coating on thecoking rate.

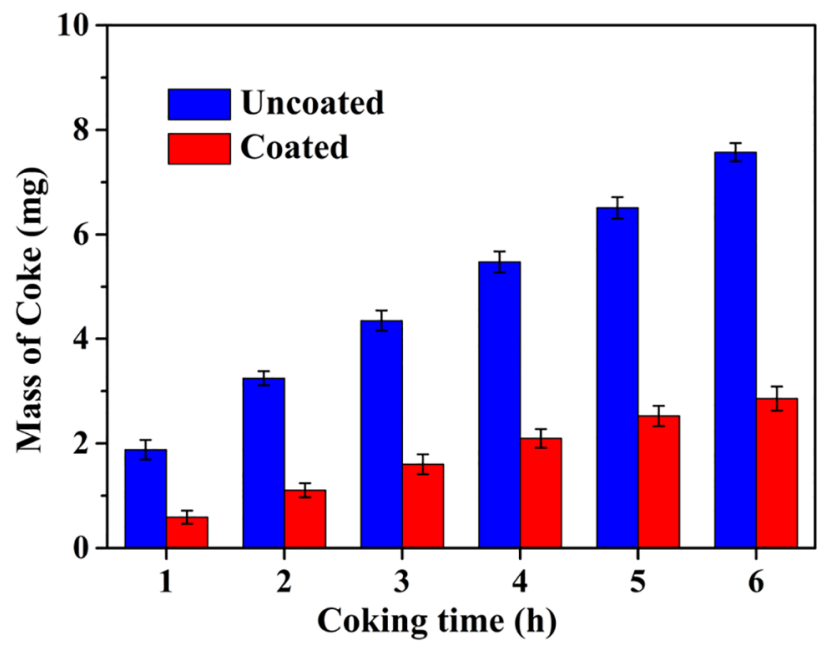

Figure 10. Coking rates of both uncoated and coated samples during 1-6 h coking time.

\section{Effect of aging on the spinel coating}

Typically, oxide scale deteriorates over time under a high temperature carbonaceous environment. Therefore, the effect of aging on the coating is another factor which deserves to be studied. Figure 11 shows the cross-sectional morphology and elemental distribution of a coated sample after 10 coking and decoking cycles. The SEM and EDS analyses reveal spinel coating, Sirich oxide beneath the coating and unburned coke on the coating. Moreover, the spinel coating is still dense and no obvious carburization can be found throughout the coating. This indicates that the spinel coating can resist well the influence of coking and decoking environments, so that the coating is not significantly affected by coking and decoking cycles, which is also proved by previous reports (Muñoz Gandarillas et al., 2014).

\section{CONCLUSIONS}

A novel two-step method to fabricate a $\mathrm{MnCr}_{2} \mathrm{O}_{4}$ spinel coating on HP 40 alloy was presented in this work. The Cr-Mn diffusion layer formed after the Cr-Mn pack cementation process is rich in $\mathrm{Cr}$, lacking $\mathrm{Fe}$ and $\mathrm{Ni}$, and with an elevated concentration of $\mathrm{Mn}$. A dense and uniform coating, fabricated by a further thermal oxidation process, is mostly composed of $\mathrm{MnCr}_{2} \mathrm{O}_{4}$ spinel, with a spot of $\mathrm{Cr}_{2} \mathrm{O}_{3}$ scattered over the coating. The cross-section analysis displays a $\mathrm{MnCr}_{2} \mathrm{O}_{4}$ spinel coating with a thickness exceeding $5 \mu \mathrm{m}$, as well as a Si-rich oxide transition layer.

The spinel coating, mainly composed of $\mathrm{MnCr}_{2} \mathrm{O}_{4}$, can eliminate catalytic coking and the morphology of coke on it is granular. The coking rate on the $\mathrm{MnCr}_{2} \mathrm{O}_{4}$ spinel coating is significantly slowed down, and the coke formed on the coating has a larger proportion of disordered graphite and amorphous carbon. Moreover, the coating is stable in coking and decoking environments.
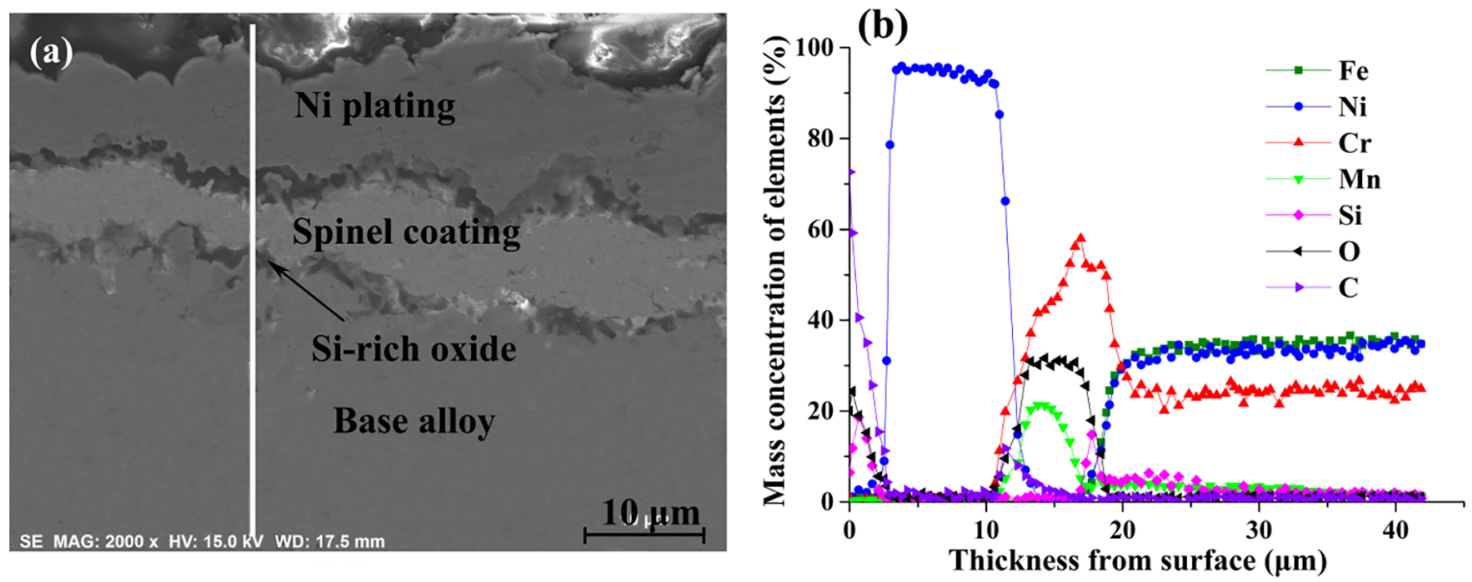

Figure 11. Cross-sectional morphology and elemental distribution of coated sample after 10 coking and decoking cycles: (a) crosssectional morphology; (b) elemental distribution of the cross-section. 


\section{ACKNOWLEDGMENTS}

This work was gratefully supported by Research Fund for the Doctoral Program of Higher Education of China (20110074110009) and Sinopec Corp., China.

\section{REFERENCES}

Albright,L. F. and Marek, J. C., Mechanistic model for formation of coke in pyrolysis units producing ethylene. Industrial \& Engineering Chemistry Research, 27 755-759 (1988).

Bao, B., Liu, J., Xu, H., Liu, B., Zhang, W., Inhibitory effect of $\mathrm{MnCr}_{2} \mathrm{O}_{4}$ spinel coating on coke formation during light naphtha thermal cracking. RSC Advances, 6 68934-68941 (2016).

Chen, Y., Liu, Z., Ringer, S. P., Tong, Z., Cui, X., Chen, $\mathrm{Y}$., Selective oxidation synthesis of $\mathrm{MnCr}_{2} \mathrm{O}_{4}$ spinel nanowires from commercial stainless steel foil. Crystal Growth and Design, 7 2279-2281 (2007).

Gupta, H. C., Sinha, M. M., Tripathi, B. B., A study of the interatomic interaction in oxide spinel $\mathrm{MnCr}_{2} \mathrm{O}_{4}$. Physica B: Condensed Matter, 192 343-344 (1993).

Horita, T., Xiong, Y., Yamaji, K., Sakai, N., Yokokawa, $\mathrm{H}$., Characterization of $\mathrm{Fe}-\mathrm{Cr}$ alloys for reduced operation temperature SOFCs. Fuel cells, 2 189-194 (2002).

Huntz, A. M., Reckmann, A., Haut, C., Sévérac, C., Herbst, M., Resende, F. C. T., Sabioni, A. C. S., Oxidation of AISI 304 and AISI 439 stainless steels. Materials Science and Engineering: A, 447 266-276 (2007).

Kawakami, M., Karato, T., Takenaka, T., Yokoyama, S., Structure analysis of coke, wood charcoal and bamboo charcoal by Raman spectroscopy and their reaction rate with CO2. ISIJ International, 45 10271034 (2005).

Li, C. and Yang, Y., A glass based coating for enhancing anti-coking and anti-carburizing abilities of heatresistant steel HP. Surface and Coatings Technology, 185 68-73 (2004).

Li, H. and Chen, W., Stability of $\mathrm{MnCr}_{2} \mathrm{O}_{4}$ spinel and $\mathrm{Cr}_{2} \mathrm{O}_{3}$ in high temperature carbonaceous environments with varied oxygen partial pressures. Corrosion Science, 52 2481-2488 (2010).

Li, H. and Chen, W., High temperature carburization behaviour of $\mathrm{Mn}-\mathrm{Cr}-\mathrm{O}$ spinel oxides with varied concentrations of manganese. Corrosion Science, 53 2097-2105 (2011).

Li, H., Zheng, Y., Benum, L. W., Oballa, M., Chen, W., Carburization behaviour of Mn-Cr-O spinel in high temperature hydrocarbon cracking environment. Corrosion Science, 51 2336-2341 (2009).

Muñoz Gandarillas, A. E., Van Geem, K. M., Reyniers, M.-F., Marin, G. B., Coking resistance of specialized coil materials during Steam cracking of Sulfurfree naphtha. Industrial \& Engineering Chemistry Research, 53 13644-13655 (2014).

Muñoz Gandarillas, A. E., Van Geem, K. M., Reyniers, M.-F., Marin, G. B., Influence of the reactor material composition on coke formation during ethane steam cracking. Industrial \& Engineering Chemistry Research, 53 6358-6371 (2014).

Monteiro, M. J., Saunders, S. R. J., Rizzo, F. C., The effect of water vapour on the oxidation of high speed steel, kinetics and scale adhesion. Oxidation of Metals, 75 57-76 (2011).

Proy, M., Utrilla, M. V., Otero, E., Bouchaud, B., Pedraza, F., Effects of Grit Blasting and Annealing on the High-Temperature Oxidation Behavior of Austenitic and Ferritic Fe-Cr Alloys. Journal of Materials Engineering and Performance, 23, 28472857(2014).

Sadezky, A., Muckenhuber, H., Grothe, H., Niessner, R., Pöschl, U., Raman microspectroscopy of soot and related carbonaceous materials: spectral analysis and structural information. Carbon, 43 1731-1742 (2005).

Sadrjahani, M., Hoseini, S. A., Mottaghitalab, V., Haghi, A. K., Development and characterization of highly oriented pan nanofiber. Brazilian Journal of Chemical Engineering, 27, 583-589(2010).

Shao, M., Cui, L., Zheng, Y., Wang, Y., Xing, L., Oxidation behavior of alloy $\mathrm{HK} 40$ in $\mathrm{H}_{2}-\mathrm{H}_{2} \mathrm{O}$ atmosphere. Materials and Corrosion, 64 777-782 (2013).

Sheng, C., Char structure characterised by Raman spectroscopy and its correlations with combustion reactivity. Fuel, 86 2316-2324 (2007).

Schietekat, C. M., Sarris, S. A., Reyniers, P. A., Kool, L. B., Peng, W., Lucas, P., Van Geem, K. M., Marin, G. B., Catalytic coating for reduced coke formation in steam cracking reactors. Industrial \& Engineering Chemistry Research, 54 9525-9535 (2015).

Tang, S., Gao, S., Hu, S., Wang, J., Zhu, Q., Chen, Y., $\mathrm{Li}, \mathrm{X}$., Inhibition effect of APCVD titanium nitride coating on coke growth during n-hexane thermal cracking under supercritical conditions. Industrial \& Engineering Chemistry Research, 53 5432-5442 (2014).

Tang, S., Wang, J., Zhu, Q., Chen, Y., Li, X., Preparation of rutile $\mathrm{TiO}_{2}$ coating by thermal chemical vapor 
deposition for anticoking applications. ACS Applied Materials \& Interfaces, 6 17157-17165 (2014).

Tang, S., Hu, S., Zhang, Y., Wang, J., Zhu, Q., Chen, $\mathrm{Y}$., Li, X., Influence of TiN coating on products distribution for hydrocarbon fuel cracking under high temperature and pressure. Journal of Analytical and Applied Pyrolysis, 107 197-203 (2014).

Wang, J., Reyniers, M.-F., Van Geem, K. M., Marin, G. B., Influence of Silicon and Silicon/SulfurContaining Additives on Coke Formation during Steam Cracking of Hydrocarbons. Industrial \& Engineering Chemistry Research, 47 1468-1482 (2008).
Wang, J., Reyniers, M.-F., Marin, G. B., Influence of Dimethyl Disulfide on Coke Formation during Steam Cracking of Hydrocarbons. Industrial \& Engineering Chemistry Research, 46 4134-4148 (2007).

Wang, Z., Xu H., Luan, X., Hou, F., Zhou, J., Effect of potassium acetate on coke growth during light naphtha thermal cracking. Industrial \& Engineering Chemistry Research, 50 10292-10297 (2011).

Zhang, Z. and Albright, L. F., Pretreatments of coils to minimize coke formation in ethylene furnaces. Industrial \& Engineering Chemistry Research, 49 1991-1994 (2010). 